\title{
An Assessment of Postmenopausal Symptoms among Hilly and Urban Populations from Chattogram Division
}

\author{
RawshanAra Begum ${ }^{1 *}$, Mohammad Ershad Alam², Nazneen Ahmed ${ }^{3}$, Sonjib Chakraborty ${ }^{4}$
}

\author{
${ }^{1}$ Senior Consultant, Department of Gynaecology and Obstetrics, Khagrachhari Adhunik Sadar Hospital, Khagrachhari, Bangladesh \\ ${ }^{2}$ Assistant Professor, Department of Surgery, Chittagong Medical College, Chattogram, Bangladesh \\ ${ }^{3}$ Junior Consultant, Department of Gynaecology and Obstetrics, Bandarban Sadar Hospital, Bandarban, Bangladesh \\ ${ }^{4}$ Independent Researcher, Manikchhari, Khagrachhari, Bangladesh
}

*Corresponding author: RawshanAra Begum

Abstract Original Research Article

Background: Postmenopausal problems in women are major issues in their health concerns where they are disturbed by several postmenopausal physical and mental health problems. Which are disrupts their quality of life and regular activities. These difficulties are more prevalent in low-income countries where knowledge is minimal in these issues. It makes significant problems. The study aims to find out discrepancies among the hilly and urban intensity of postmenopausal challenges. Methods: In this study, self-administered questionnaires were used to get information about menopausal women in the urban and hilly areas. A total of 200 women's general information, including social status, vasomotor and psychosomatic state was collected. All accumulated data were documented and analyzed in the IBM Statistical Package for Social Science (SPSS) version 26.0. Results: A Pearson chi-square test was performed to examine the relationship between location and other variables, where the level of significance $p<0.05$. The result shows that, Emotional Sensitivity: $p>0.000$, Irritability: $p>0.048$, Trouble of Recalling Memories: $p>0.032$, Bone Pain: $p>0.002$, Numbness of Fingers: $p>0.015$, Frequent Urination: $p>0.001$, Leaky Bladder: $p>0.010$. Conclusion: Significant differences of symptoms were observed in between women of Hilly and Urban area. These difficulties may hamper regular activities, so women should be aware of it and manage this situation smoothly and establish a quality lifestyle.

Key words: Menopause, Gynecological problems, psychosomatic state, Quality of life, Women's health.

Copyright $(\odot 2021$ The Author(s): This is an open-access article distributed under the terms of the Creative Commons Attribution 4.0 International License (CC BY-NC 4.0) which permits unrestricted use, distribution, and reproduction in any medium for non-commercial use provided the original author and source are credited.

\section{INTRODUCTION}

Menopause is a crucial process in women's lives during 40-60 years of age where fertility and ovarian activity are reduced and resulting in various physical and psychological symptoms, including irregular menstrual interims [1,2]. The menopause transitional indicates the initial loss of the follicle and the hormonal dependence of reproductive aging. Simultaneously, a responsive ovary remains and an eventual complete loss of follicle response, with persistent hypergonadotropic amenorrhea, instant ovarian hormone negatively reacts with reproductive organs and entire body due to lack of estrogen [3, 4]. The process of menopause is usually observed from middle age which is one-third of a woman's total life span. Menopause starts with the cessation of ovarian function and leads to the reproductive system's termination. When a woman reaches middle age, estrogen and progesterone production decayed and onwards most women face various vasomotor symptoms and psychosomatic difficulties that can be severe in some individuals. Certain difficulties are habitually let by hormonal imbalances, notably Hot Flush, Night Sweating, Anxiety, Sleep Disturbances, Muscles and Joints pain, Formication, Frequent Urination, and many more [5-7]. One of the studies explains that the most basic physical and psychological discomforts were Headache $(88.80 \%)$, Joint and muscular problems $(76.20 \%)$, Sleep disruption $(44.40 \%)$. These are found high intensity while sexual, bladder, and cardiac difficulties are less reported [8]. Difficulties associated with menopause can also vary because of the diverse lifestyle. A study found disparities among hilly and urban areas, with night sweating $41.2 \%$ in urban areas and $13.7 \%$ in hilly areas, mild disturbances $47.0 \%$ in urban and $24.6 \%$ in hilly, musculoskeletal problems in urban $69.2 \%$ and hilly $29.2 \%$. Frequent fractures were observed only in hilly areas, $29.2 \%$ against which was $0.0 \%$ in urban areas [7]. 
RawshanAra Begum et al; Sch J App Med Sci, Feb, 2021; 9(2): 206-211

The present investigation aims to find out discrepancies among the hilly and urban intensity of postmenopausal challenges.

\section{METHODS}

The present cross-sectional study using selfadministered questionnaires was conducted in July 2020 and completed in October 2020, where 200 women from the Khagrachhari hills tract and Chattogram district, as a hilly and urban area in the age group between 40-60 years, were selected through stratified random sampling. Data were collected using social and symptoms related questionnaires, including psychosomatic difficulties and secondary data collected from the journal articles and books. 07 samples were deducted from the total population; due to lack of data accuracy and privacy concern; finally, 193 individuals computed in Statistical Package for Social Science (SPSS) version 26.0 for data interpretation and analysis. A Pearson chi-square test was performed to examine the relationship between hilly and urban. The level of $p$ value considered value significance is $\mathrm{p}<0.05$.

\section{RESULT}

The total postmenopausal population reflected in this study where 96 represent their information from the hilly area, and 97 denote from urban areas. The table-1 elucidates the frequency, percentage, minimum, maximum, and means distribution of postmenopausal participants of the total population and sub-divided by hilly and urban groups of their age background. In the $45-<50$ years age group are high at a frequency, which is 65.80 percent, mean 48.57 . The notable data showed at the age of me Menarche, group 9-12 Years, which are hilly $8.33 \%$ and urban $34.02 \%$ and Age of Menopause recorded age group 50-<55 years are 1.04 at hilly and 7.22 at urban. Figure1 and Figure2 Shown the urban women are highly employed and literate than hilly.

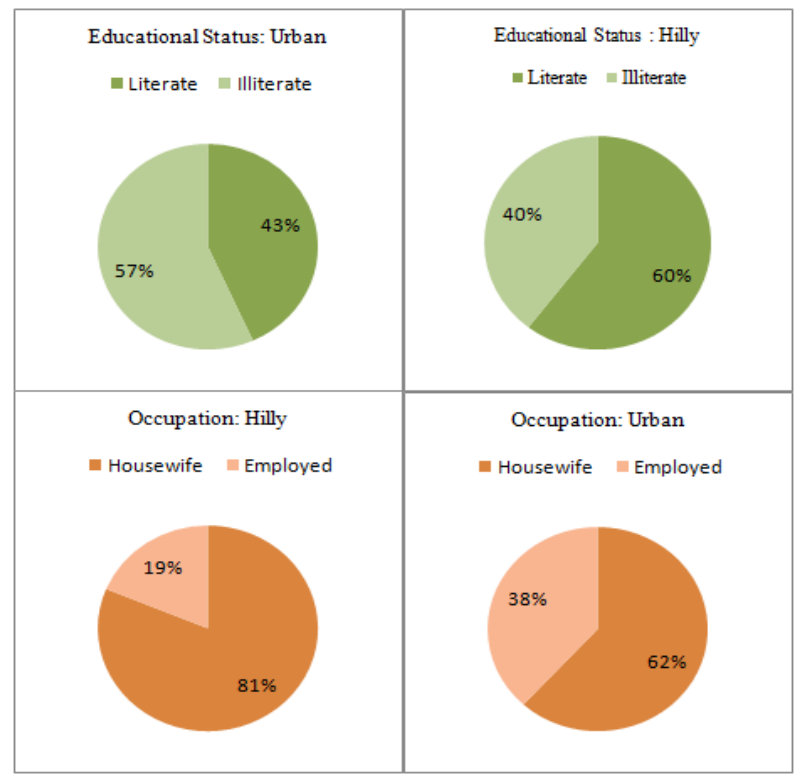

Fig-1

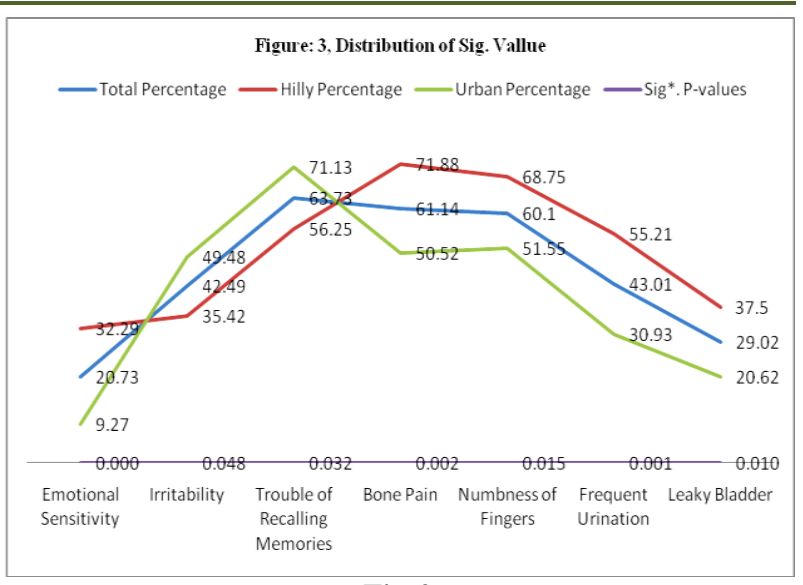

Fig-2

Figure: $1 \& 2$ (Educational and Occupational Status: hilly and urban area)

The Pearson chi-square test was performed to examine the relationship between location and distribution of participants' frequency and percentage according to their postmenopausal symptoms and discomfort in this table-2. It shows the percentage of the total population divided by hilly and urban respondents with the $p$-value (Level of significance $p<0.05$ ).

Despite the highest frequency and percentage found in the hilly and urban area at the variable hot flush. Also found 7 variables are statically significant, p-value are Emotional Sensitivity: p>0.000; Trouble recalling memories: $p>0.032$; Irritability: $p>0.048$, Bone Pain: $p>0.002$; Numbness of Fingers: $p>0.015$; Frequent Urination: $p>0.001$; Leaky Bladder: $p>0.010$. The other variables are comparatively the same at the given table, and there is no significant relationship between these with the location.

The given line graph (Figure-3) illustrates significant data about Psychological Symptoms, Psychosomatic Symptoms, and Urinary Problem. The differences between frequency to frequency and percentage to percentage are shown with the p-value. The category Emotional Sensitivity, Irritability, and Trouble recalling memories are shown as Psychological Symptoms; Bone Pain, Numbness of Fingers are represented as psychosomatic symptoms. Urinary Problem denotes in the graph with two categories which are, Frequent Urination and Leaky Bladder. All the pvalues are conferred by the level of significance $p<0.05$.

\section{DisCUSSION}

Several factors cause various physical and psychological health complications in postmenopausal women, which hampers their quality lifestyle [13]. This study tries to uncover the symptoms in the hilly and urban populations. The outcome from the study obtained, some categories are high at hilly, and some are urban population such as emotional sensitivity, bone pain, Numbness of Fingers, Frequent Urination and 
RawshanAra Begum et al; Sch J App Med Sci, Feb, 2021; 9(2): 206-211

Leaky Bladder indicate high percentage at the hilly area, in contrast, Trouble of Recalling Memories, Irritability are mentioned high at the urban result. These two problems are more prevalent in urban populations [7].Hot flush was noted at almost four-third; comparatively, one of the Indian studies has shown similar according to the data obtained from their respondents and percentages nearby to our findings another Premenopausal and postmenopausal comparative study for postmenopausal women by K, Shilpa \& Ugargol, Amit. And Sharma, S., \& Mahajan, $\mathrm{N}$ [7, 18] and contradictory to our findings reported these study by Sagdeo, M \&Arora, Dimple., Sharma S, Tandon V, Mahajan A., Mahajan, N., Aggarwal, M., \&Bagga, A [5, 17, 23]. A Thai study by Punyahotra, S., Dennerstein, L., \& Lehert, P. showed a percentage of total night sweating of a quarter which fully supports our study-moreover, Sagdeo, M \& Arora, Dimple. Represent the symptoms differently; the percentage of urban and rural is almost multiplying that of the current study $[28,6]$. According to the National Health ServiceUK, hotflashes are usually harmless and caused by hormonal changes in women, which can last from several months before the last menstrual period to several years after menopause and trigger several factors [26]. Estrogen-based hormone therapy is most efficient for hot flashes and night sweats but with several side-effects.

Whatever, Hot flashes and night sweats reduces by supporting non-hormonal treatment, including medications such as antidepressants, nerve pain, and high blood pressure medications. Stress reduction methods may also be used, such as meditation and mindfulness [25].
Anxiety is a common mental state that most postmenopausal women experience. Every woman experiences it differently, which a health care provider can identify, and a completely different treatment plan can be made for each [32]. There are several studies on the relationship between anxiety and menopause; however, according to Bryant, C., Judd, F. K., \& Hickey, M, it is relatively inadequate [31]. In the result section, anxiety expresses just under half at hilly and almost nearly in urban. Similar data found by K, Shilpa \& Ugargol, Amit [7]. Which is just over a half in both locational data. Sharma, S., \&Mahajan, N. indicate their study result with a significant proportion in both places and the current study's contrast [18]. Eastern Indian study by Dasgupta, Doyel \& Ray, Subha.shown similar results with the current research, but slightly high with the urban population [27] other findings from the northwestern study by Sharma S, Tandon V, Mahajan, the results completely different[17]. Different articles by Mahajan, N., Aggarwal, M., \& Bagga, A. presents a minority percentage found in the category of poor concentration [23]. Heart palpitations usually increase with the onset of anxiety [33]. Heart palpitations reported by K, Shilpa\&Ugargol, Amit. were almost the same as this study, we also found double in this category at the study conducted by Dasgupta, Doyel \& Ray, Subha. In the eastern Indian part [7, 27].Emotional Sensitivity and self-esteem are individuals' mental state related to emotions, knowledge, lifestyle, and behavior [29]. These categories are less common in the menopausal related study in the subcontinent. The current study indicates that emotional sensitivity is almost triple in the hilly area than in urban, and both categories show one-fifth of total respondents. As we compared with self-esteem, it describes high at urban than hilly.

Table-1: Age distribution of Respondents

\begin{tabular}{|c|c|c|c|c|c|c|c|c|c|c|c|c|c|c|c|}
\hline & \multicolumn{5}{|c|}{ Total Population, n 200} & \multicolumn{5}{|c|}{ Hilly, n96 } & \multicolumn{5}{|c|}{ Urban, n97 } \\
\hline Age & Fre. & $(\%)$ & Min & Max & Mean & Fre. & $(\%)$ & Min & Max & Mean & Fre & $(\%)$ & Min & Max & Mean \\
\hline $40-<45$ & 4 & 2.07 & \multirow{4}{*}{42} & \multirow{4}{*}{57} & \multirow{4}{*}{48.78} & 3 & 3.13 & \multirow{4}{*}{42} & \multirow{4}{*}{53} & \multirow{4}{*}{48.39} & 1 & 1.03 & \multirow{4}{*}{44} & \multirow{4}{*}{57} & \multirow{4}{*}{49.16} \\
\hline $45-<50$ & 127 & 65.80 & & & & 68 & 70.83 & & & & 59 & 60.82 & & & \\
\hline $50-<55$ & 58 & 30.05 & & & & 25 & 26.04 & & & & 33 & 34.02 & & & \\
\hline $55-<60$ & 4 & 2.07 & & & & - & - & & & & 4 & 4.12 & & & \\
\hline \multicolumn{16}{|c|}{ Age of Menarche } \\
\hline $9-12$ & 41 & 21.24 & \multirow{3}{*}{11} & \multirow{3}{*}{16} & \multirow{3}{*}{13.16} & 8 & 8.33 & \multirow{3}{*}{11} & \multirow{3}{*}{16} & \multirow{3}{*}{13.55} & 33 & 34.02 & \multirow{3}{*}{11} & \multirow{3}{*}{14} & \multirow{3}{*}{12.76} \\
\hline $13-15$ & 150 & 77.72 & & & & 86 & 89.58 & & & & 64 & 65.98 & & & \\
\hline$>15$ & 2 & 1.04 & & & & 2 & 2.08 & & & & - & - & & & \\
\hline \multicolumn{16}{|c|}{ Age of Menopause } \\
\hline $40-<45$ & 16 & 8.29 & \multirow{3}{*}{41} & \multirow{3}{*}{54} & \multirow{3}{*}{46.24} & 9 & 9.38 & \multirow{3}{*}{42} & \multirow{3}{*}{51} & \multirow{3}{*}{45.97} & 7 & 7.22 & \multirow{3}{*}{41} & \multirow{3}{*}{54} & \multirow{3}{*}{46.51} \\
\hline $45-<50$ & 169 & 87.56 & & & & 86 & 89.58 & & & & 83 & 85.57 & & & \\
\hline $50-<55$ & 8 & 4.15 & & & & 1 & 1.04 & & & & 7 & 7.22 & & & \\
\hline
\end{tabular}


RawshanAra Begum et al; Sch J App Med Sci, Feb, 2021; 9(2): 206-211

Table-2: Distribution of participant's frequency and percentage according to their postmenopausal symptoms and discomforts and Pearson Chi-Square performed. * Level of significance $\mathbf{p}<0.05$, NS- Not Significant

\begin{tabular}{|c|c|c|c|c|c|c|c|c|}
\hline \multirow{2}{*}{\multicolumn{2}{|c|}{$\begin{array}{l}\text { Table-2 } \\
\text { Characteristics and Symptoms }\end{array}$}} & \multicolumn{2}{|c|}{$\begin{array}{l}\text { Total } \\
\text { Population }\end{array}$} & \multicolumn{2}{|c|}{ Hilly } & \multicolumn{2}{|c|}{ Urban } & \multirow{2}{*}{$\begin{array}{l}\text { Pearson } \\
\text { Chi-Square } \\
p^{*}\end{array}$} \\
\hline & & Fre. & $(\%)$ & Fre. & $(\%)$ & Fre. & $(\%)$ & \\
\hline \multirow{2}{*}{$\begin{array}{l}\text { Vasomotor } \\
\text { Symptoms }\end{array}$} & Hot Flush & 137 & 70.98 & 64 & 66.67 & 73 & 75.26 & $\mathrm{NS}$ \\
\hline & Night Sweating & 49 & 25.39 & 22 & 22.92 & 27 & 27.84 & $\mathrm{NS}$ \\
\hline \multirow{6}{*}{$\begin{array}{l}\text { Psychological } \\
\text { Symptoms }\end{array}$} & Anxiety & 88 & 45.6 & 47 & 48.96 & 41 & 42.27 & $\mathrm{NS}$ \\
\hline & Poor Concentration & 129 & 66.84 & 59 & 61.46 & 70 & 72.16 & NS \\
\hline & Emotional Sensitivity & 40 & 20.73 & 31 & 32.29 & 9 & 9.27 & $0.000 *$ \\
\hline & Irritability & 82 & 42.49 & 34 & 35.42 & 48 & 49.48 & $0.048 *$ \\
\hline & Self Esteem & 44 & 22.8 & 17 & 17.71 & 27 & 27.84 & NS \\
\hline & Trouble of Recalling Memories & 123 & 63.73 & 54 & 56.25 & 69 & 71.13 & $0.032 *$ \\
\hline \multirow{11}{*}{$\begin{array}{l}\text { Psychosomatic } \\
\text { Symptoms }\end{array}$} & Bone Pain & 118 & 61.14 & 69 & 71.88 & 49 & 50.52 & $0.002 *$ \\
\hline & Dizziness & 125 & 64.77 & 62 & 64.58 & 63 & 64.95 & NS \\
\hline & Rapid Heartbeat & 84 & 43.52 & 46 & 47.92 & 38 & 39.18 & NS \\
\hline & Numbness of Fingers & 116 & 60.1 & 66 & 68.75 & 50 & 51.55 & $0.015 *$ \\
\hline & Tingling of Fingers & 97 & 50.26 & 45 & 46.88 & 52 & 53.61 & NS \\
\hline & Cold Hand and Feet & 92 & 47.67 & 41 & 42.71 & 51 & 52.58 & NS \\
\hline & Headache & 85 & 44.04 & 46 & 47.92 & 39 & 40.21 & NS \\
\hline & Sleep Disturbances & 135 & 69.95 & 65 & 67.71 & 70 & 72.16 & $\mathrm{NS}$ \\
\hline & Muscles and Joints Pain & 138 & 71.5 & 68 & 70.83 & 70 & 72.16 & NS \\
\hline & Mastalgia & 45 & 23.32 & 24 & 25 & 21 & 21.65 & NS \\
\hline & Formication & 46 & 23.83 & 27 & 28.13 & 19 & 19.59 & NS \\
\hline \multirow{2}{*}{$\begin{array}{l}\text { Urinary } \\
\text { Problem }\end{array}$} & Frequent Urination & 83 & 43.01 & 53 & 55.21 & 30 & 30.93 & $0.001 *$ \\
\hline & Leaky Bladder & 56 & 29.02 & 36 & 37.5 & 20 & 20.62 & $0.010 *$ \\
\hline
\end{tabular}

Sleep disorders are most common in menopausal women, with many causes: vasomotor symptoms and hormonal label changes are the main culprits - a study Freedman, R. R., \& Roehrs, T. A. Say half of the main population of menopausal people have sleep apnea, as sleep disorder mentioned in Sharma, S., \& Mahajan, N. is equivalent to this study, but another one by Ahmed, Sultana. In the Northeast part of India, their respondents were below half-percent, and from a Different study by Mahajan, N., Aggarwal, M., \& Bagga, A. affirmed that was less than the previous study [34, 18, 22, 23]. Holly L. Thacker, MD; express that declining estrogen levels from either menopause can affect brain function and cause these momentary recall failures [36]. The trouble of recalling memory we found a significant proportion of a large majority at urban people is statistically significant.A comparative study on postmenopausal symptoms in rural and urban women by K, Shilpa\&Ugargol, Amit. rollout the same percentage with us except one-fifth at rural whereas, menopausal symptoms in urban women by Sharma $S$, Tandon V, Mahajan A. told in a study it is almost half than the current study [7, 17]. Most of menopausal women suffer joint pain after menopause. Menopause plays an important role in muscle and joint function, known as musculoskeletal health presentation with Osteoarthritis, osteoporosis and Sarcopenia, stimulated by estrogen insufficiency [37, 38]. Study shown that very large majority are suffering muscle and jointrelated difficulties where hilly and urban population reveals almost similar percentages. K, Shilpa \& Ugargol, Amit. and Sharma, S., \& Mahajan, N. 's study indicates the imminent percentages but A Study to Assess the Psychosomatic Problems of Postmenopausal Women in Slums of Dibrugarh Town, Assam by Ahmed, Sultana. Represents just up to a half [18, 7, 22].

Multiple studies have explained that women who go through post-menopausal transitions are more prone to dizziness. This is associated with various physical and psychological factors [39] in this study, dizziness reported almost two-thirds of the total population and the same percentage found in urban and hilly areas. Dasgupta, Doyel \& Ray, Subha denotes in their study nearby percentages as our study but another study by Ledésert, B., Ringa, V., \& Bréart, G. Represent one-fourth of the total respondent [27, 5]. A study on menopausal status classified headaches category among women aged 40-54 who regularly visited the Headache Clinic [40].We found nearly a half at the subject population, but it has a few high percentages at the hilly area. Shakhatreh, F. M., \& Mas'ad, D. manifested data in their study, which concerns almost the same percentages compared to the current study whereas, Ledésert, B., Ringa, V., \& Bréart, G. and K, Shilpa \& Ugargol, Amit. shown onethird of the total population in their result. And Menopausal Problems among Rural and Urban Women from Eastern India by Dasgupta, Doyel \& Ray, Subha.represent almost two-thirds of the rural population [24, 5, 7, 27].According to Johns Hopkins Medicine, Psychological and emotional symptoms of irritability are linked to the deficiency of estrogen production. According to Johns Hopkins Medicine, 
RawshanAra Begum et al; Sch J App Med Sci, Feb, 2021; 9(2): 206-211

Psychological and emotional symptoms of irritability linked to the deficiency of estrogen production. Some of the studies K, Shilpa \& Ugargol, Amit, Ahmed, Sultana and Mahajan, N., Aggarwal, M., \& Bagga, A are shown related result at irritability with current findings. Whereas another separate study by Sharma, S., \& Mahajan, N. and Dasgupta, Doyel \& Ray, Subha presented different results, which are a vast majority of the population denotes with symptoms irritability [7, 22, $23,18,27]$.Investigation identifies the formication, or skin crewels denotes one-fifth of the total population and a similar study- title; Menopausal symptoms in urban women by Sharma S, Tandon V, Mahajan A., but according to toa north Indian study 'Health issues of menopausal women in North India' by Mahajan, N., Aggarwal, M., \& Bagga, A. found one in ten at their total hilly population $[17,23]$. Breast pain, tenderness, heaviness, tightness considered as medical term Mastalgia. Most of the women face this at the age of 15 to 40. The study said nearly two-thirds of women experience Mastalgiaat their reproductive time and also seeking medical assistance. The cyclic Mastalgiais connected with the women's menstrual cycle. Ledésert, B., Ringa, V., \& Bréart, G.'s result match with this study; it is almost one-fourth of the entire participants and Dasgupta, Doyel \& Ray, Subha represent just a little high of one-fourth $[41,5,27]$.Urinary problem is a significant concern of postmenopausal women that influence more than half of the total population. The result of this study identifies almost the same case. Whereas one study said it is one-third of the total study's population $[5,7,42]$.

\section{CONCLUSION}

This study observed a prevalence of multiple postmenopausal physical and mental problems in women, which are seen differently between Urban and Hilly, where Hilly women experience more problems than Urban. In most cases, these problems remain uncovered. It is essential to build knowledge and awareness among women where these problems can immediately recognize and demand appropriate care, which can be counseling, hormonal therapy, symptomatic medication or meditation.

\section{REFERENCES}

1. Ceylan B, Özerdoğan N. Factor's affecting age of onset of menopause and determination of quality of life in menopause. Journal of Turkish Society of Obstetrics and Gynecology. 2015;12(1):43-49.

2. Singh A, Arora A. Profile of menopausal women in rural north India. Climacteric. 2005;8(2):177-184.

3. Santoro N, Randolph J. Reproductive Hormones and the Menopause Transition. Obstetrics and Gynecology Clinics of North America. 2011;38(3):455-466.

4. Blumel, J E, Castelo-Branco C, Binfa L, Gramegna G., Tacla X0, Aracena B, Cumsille, M A, Sanjuan
A. Quality of life after the menopause: a population study. Maturitas, 2000: 34(1).

5. Ledésert B, Ringa V, Bréart G. Menopause and perceived health status among the women of the french GAZEL cohort. Maturitas. 1994;20(23):113-120.

6. M.M. Sagdeo, Dimple Arora. Menopausal Symptoms:A Comparative Study in Rural and Urban Women. J K Sc.2011:13(1):23-26.

7. K S, Ugargol A. A comparative study on postmenopausal symptoms in rural and urban women. International Journal of Community Medicine and Public Health. 2015;:604-609.

8. Rahman S, Salehin F, Iqbal A. Menopausal symptoms assessment among middle age women in Kushtia, Bangladesh. BMC Research Notes. 2011;4(1).

9. Ismail H, Fayaz F, Ismail N. Knowledge and perception of postmenopausal women towards menopause. International Journal of Research in Medical Sciences. 2020;8(11):3920.

10. Dasgupta D, Karar P, Ray S, Ganguly N. Menopausal Symptoms and Its Correlates: A Study on Tribe and Caste Population of East India. Current Gerontology and Geriatrics Research. 2015;2015:1-7.

11. AIRY L, ADIGA S, BHAT P, BHAT R. Prevalence of menopausal symptoms and quality of life after menopause in women from South India. Australian and New Zealand Journal of Obstetrics and Gynaecology. 2009;49(1):106-109.

12. Kumar Mishra S. Menopausal transition and postmenopausal health problems: a review on its bio-cultural perspectives. Health. 2011;03(04):233237.

13. Karaçam Z, Şeker S. Factors associated with menopausal symptoms and their relationship with the quality of life among Turkish women. Maturitas. 2007;58(1):75-82.

14. Gharaibeh M, Al-Obeisat S, Hattab J. Severity of menopausal symptoms of Jordanian women. Climacteric. 2010;13(4):385-394.

15. Soares C. Menopausal transition and depression: who is at risk and how to treat it? Expert Review of Neurotherapeutics. 2007;7(10):1285-1293.

16. Almeida O, Marsh K, Flicker L, Hickey M, Ford A, Sim M. Reducing depression during the menopausal transition: study protocol for a randomised controlled trial. Trials. 2014;15(1).

17. Sharma S, Tandon V, Mahajan A. Menopausal symptoms in urban women. 2007:9(1).

18. Sharma S, Mahajan N. Menopausal symptoms and its effect on quality of life in urban versus rural women: A cross-sectional study. Journal of Midlife Health. 2015;6(1):16.

19. Bielawska-BE. The Psychology of the Menopause: The Experiences during the Transition and Individual Conceptualization of Menopause. Nutrition and Diet in Menopause. Humana Press. $2013: 333-345$. 
RawshanAra Begum et al; Sch J App Med Sci, Feb, 2021; 9(2): 206-211

20. Brambilla D, McKinlay S. A prospective study of factors affecting age at menopause. Journal of Clinical Epidemiology. 1989;42(11):1031-1039.

21. Defey D, Storch E, Cardozo S, Díaz O, Fernández G. The menopause: Women's psychology and health care. Social Science \& Medicine. 1996;42(10):1447-1456.

22. Ahmed, Sultana. A Study to Assess the Psychosomatic Problems of Postmenopausal Women in Slums of Dibrugarh Town, Assam. International Journal of Contemporary Medical Research. 2017:4

23. Mahajan N, Aggarwal M, Bagga A. Health issues of menopausal women in North India. Journal of Mid-life Health. 2012;3(2):84.

24. Shakhatreh F, Mas'ad D. Menopausal symptoms and health problems of women aged 50-65 years in Southern Jordan. Climacteric. 2006;9(4):305-311.

25. Ferrari N. Menopause-related hot flashes and night sweats can last for years - Harvard Health Blog [Internet]. Harvard Health Blog. 2021 [cited 1 January 2021]. Available from: https://www.health.harvard.edu/ blog/menopauserelated-hot-flashes-night-sweats-can-last-years201502237745

26. Menopause - Hot flushes [Internet]. nhs.uk. 2021 [cited 1 January 2021]. Available from: https://www.nhs.uk/conditions/menopause/hotflushes/

27. Dasgupta D. Ray S. Menopausal Problems among Rural and Urban Women From Eastern India. Journal of Social, Behavioral, and Health Sciences.2009:3(1):20-33

28. Punyahotra S, Dennerstein L, Lehert P. Menopausal experiences of Thai women. Part 1: Symptoms and their correlates. Maturitas. 1997;26(1):1-7.

29. Chedraui P, Pérez-López F, Mendoza M, Leimberg M, Martinez M, Vallarino V. Assessment of selfesteem in mid-aged women. Maturitas. 2010;66(1):77-82.

30. Publishing $H$. Dealing with the symptoms of menopause - Harvard Health [Internet]. Harvard Health. 2021 [cited 19 December 2020]. Available from: https://www.health.harvard.edu/womenshealth/dealing-with-the-symptoms-of-menopause
31. Bryant C, Judd F, Hickey M. Anxiety during the menopausal transition: A systematic review. Journal of Affective Disorders. 2012;139(2):141148.

32. Bremer E, Jallo N, Rodgers B, Kinser P, Dautovich N. Anxiety in Menopause: A Distinctly Different Syndrome. The Journal for Nurse Practitioners. 2019;15(5):374-378.

33. Publishing H. Heart Palpitations - Harvard Health [Internet]. Harvard Health. 2021 [cited 3 December 2020]. Available from: https://www.health.harvard.edu/decision_guide/hea rt-palpitations

34. Freedman RR, Roehrs TA. Sleep disturbance in menopause. Menopause. 2007:14(5):826-9.

35. Ameratunga D, Goldin J, Hickey M. Sleep disturbance in menopause. Internal Medicine Journal. 2012;42(7):742-747.

36. Memory Loss in Women - Is It Age or Menopause? [Internet]. Health Essentials from Cleveland Clinic. 2021 [cited 5 January 2021]. Available from: https://health.clevelandclinic.org/memory-loss-inmiddle-aged-women-is-it-age-or-menopause/

37. Watt F. Musculoskeletal pain and menopause. Post Reproductive Health. 2018;24(1):34-43.

38. Khadilkar S. Musculoskeletal Disorders and Menopause. The Journal of Obstetrics and Gynecology of India. 2019;69(2):99-103.

39. Terauchi M, Odai T, Hirose A, Kato K, Akiyoshi M, Masuda M. Dizziness in peri- and postmenopausal women is associated with anxiety: a cross-sectional study. BioPsychoSocial Medicine. 2018;12(1).

40. Oh K, Jung K, Choi J, Seo W, Park K. Headaches in Middle-Aged Women during Menopausal Transition: A Headache Clinic-Based Study. European Neurology. 2012;68(2):79-83.

41. Muhammad T. Tahir; Shafeek Shamsudeen. Mastalgia. StatPearls Publishing. 2020: Available from:

https://www.ncbi.nlm.nih.gov/books/NBK562195/

42. Kołodyńska G, Zalewski M, Rożek-Piechura K. Urinary incontinence in postmenopausal women causes, symptoms, treatment. Menopausal Review. 2019;18(1):46-50. 